\title{
ORGANISMOS E PRESSÃO SOCIAL INTERNACIONAL: UMA RELEITURA A PARTIR DO DIREITO COMPORTAMENTAL
}

\author{
ORGANIZATIONS AND INTERNATIONAL SOCIAL PRESSURE: A RELEASE \\ FROM BEHAVIORAL LAW
}

\author{
Henrique Ribeiro Cardoso ${ }^{1}$ \\ Alberto Hora Mendonça Filho
}

\begin{abstract}
RESUMO
A liberdade é objeto de reflexão literária, jurídica, política e filosófica, sendo assim um direito humano, previsto na Declaração Universal dos Direitos Humanos, e fundamental segundo a Constituição Federal de 1988. No entanto, estudos recentes questionam o quando de liberdade existe na hora de escolher algo. Muito embora o direito parta da premissa de uma racionalidade normal, surgem propostas por uma análise comportamental do Direito. O mesmo pode ocorrer no direito internacional, mormente no que diz respeito à efetividade das normas e decisões internacionais. Dito isso, o presente trabalho objetiva a analisar criticamente a (im)possibilidade e (des)importância do estudo comportamental para o Direito Internacional. A título de hipótese, entende-se que a aplicação do viés comportamental no Direito é instrumento para efetivação da tutela internacional dos direitos humanos. Utiliza-se, para tanto, uma pesquisa qualitativa, sendo bibliográfica-documental, já que foram consultados artigos científicos e obras jurídicas, como regras legais, convencionais e constitucionais. Adotou-se ainda o método dedutivo. Conclui-se que o direito internacional comportamental pode auxiliar no entendimento do direito internacional em si e da atuação dos estados, bem como na efetivação das decisões dos Tribunais Internacionais.

Palavras-chave: Aplicabilidade das decisões internacionais. Direito Comportamental. Direito Internacional. Sujeitos.
\end{abstract}

\footnotetext{
ABSTRACT

Freedom is the object of literary, juridical, political and philosophical reflection, thus being a human right, foreseen in the Universal Declaration of Human Rights, and fundamental according to the Federal Constitution of 1988. However, recent studies question the when there is freedom in the hour to choose something. Although the law starts from the premise of a normal rationality, proposals come from a behavioral analysis of the Law. The same can occur

${ }^{1}$ Doutor em Direito, Estado e Cidadania (UGF/Rio), com Pós-doutorado em Democracia e Direitos Humanos (IGC - Universidade de Coimbra) e Pós-doutorado em Direitos Humanos e Desenvolvimento (PPGCJ/UFPB); Mestre em Direito, Estado e Cidadania (UGF/Rio); Especialista em Direito Constitucional Processual (FAPESE/UFS); Graduado em Direito pela Universidade Estadual de Santa Cruz (UESC/Bahia); Professor do Programa de Pós-graduação da Universidade Federal de Sergipe (Mestrado/PRODIR/UFS); Professor de Programa de Pós-graduação da Universidade Tiradentes (Mestrado/PPGD/UNIT); Professor da Escola Superior do Ministério Público de Sergipe (ESMP/SE); Membro da Academia Sergipana de Letras Jurídicas (ASLJ/SE); Promotor de Justiça em Sergipe.

${ }^{2}$ Advogado. Mestre em Direitos Humanos pela Universidade Tiradentes (UNIT/SE). Bacharel em Direito pela UNIT/SE. Integrante do Grupo de Pesquisa "Novas tecnologias e o impacto nos Direitos Humanos", presente no diretório do CNPq. Organizador do Grupo de Estudos Pontes de Miranda.
} 
in international law, especially with regard to the effectiveness of international norms and decisions. That said, the present work aims to critically analyze the (im) possibility and (dis) importance of the behavioral study for International Law. As a hypothesis, it is understood that the application of behavioral bias in the law is an instrument for effecting the international protection of human rights. For this purpose, a qualitative research is used, being bibliographical-documentary, since scientific articles and juridical works were consulted, such as legal, conventional and constitutional rules. The deductive method was also adopted. It is concluded that international behavioral law can help in the understanding of international law itself and of the states' performance, as well as in the enforcement of the decisions of the International Tribunals.

Keywords: Behavioral Law. International decision's aplicability. International Law. Subjects.

\section{INTRODUÇÃO}

Com a globalização, nota-se uma maior interdependência entre os Estados-nações no mundo. Visto isso, após os horrores do nazi fascismo, surge, como resposta, um movimento pela internacionalização dos Direitos Humanos.

No entanto, para a efetivação da tutela internacional dos Direitos Humanos, emergem algumas dificuldades e desafios, como é o caso da necessidade de (re)conceituação da soberania. De tal modo, considerando ainda a predileção pela solução pacífica dos conflitos, autores como Broude, Van Aaken, Teichman e Zamir propõem o intercâmbio das noções do direito comportamental também na esfera internacional, o que classificam como international behavioral law (direito internacional comportamental, numa tradução livre). Isso em razão da incredulidade quanto à perfeita e normal racionalidade dos sujeitos internacionais nas suas condutas.

O presente trabalho objetiva, então, a analisar criticamente a (im)possibilidade e (des)importância do estudo comportamental para o Direito Internacional. Especificamente, explicar no que consistiria a proposta do direito comportamental; demonstrar o estado da arte do Direito Internacional e os desafios na proteção aos direitos humanos; apresentar os benefícios de uma abordagem comportamental do Direito Internacional.

Adota-se, a título de hipótese, a relevância da aplicação do viés comportamental também no Direito Internacional, em virtude da sua possível contribuição na leitura e estratégia de sua formulação, bem como na efetivação da tutela internacional dos direitos humanos.

Trata-se de uma pesquisa qualitativa, porque a intenção consiste em explorar o conjunto complexo de fatores que envolvem o fenômeno central. Ainda é bibliográficadocumental, quanto ao procedimento, na medida em que se vale tanto de artigos científicos e obras doutrinários, como de regras legais, convencionais e constitucionais. Para atingir o escopo deste artigo adota-se o método dedutivo, haja vista que da perspectiva jurídico-comportamental, 
buscam-se conclusões formais a partir de tal marco teórico.

Isto posto, inicialmente, descreve-se o grande valor atribuído a liberdade entre os variados campos do conhecimento e da cultura humana, a exemplo, da política, arte e do direito. Posteriormente, indica-se como esse conceito está sendo reconstruído conforme os recentes estudos do Direito Comportamental. Depois, demonstra-se o estado de arte e as premissas do Direito, em especial, do Direito Comportamental. Finalmente, explica-se como seria e os benefícios do direito internacional comportamental.

\section{LIBERDADE: PARA ALÉM DOS PARADIGMAS MODERNOS}

No curso da história, a liberdade constitui perene objeto da inflexão humana desde a literatura, dogmática jurídica, política e filosofia. Não por acaso a primeira palavra do slogan da Revolução Francesa, que ecoou ao redor do globo, era a liberdade - acompanhada, em seguida, dos brados de igualdade e fraternidade (HOBSBAWN, 2012).

Tempos antes, em Dom Quixote, famosa obra literária do escritor espanhol Miguel de Cervantes (1547-1616), o protagonista coloca a liberdade, junto com a honra, como os bens mais valiosos que há, sendo, por eles, um dever arriscar à vida:

\footnotetext{
- La libertad, Sancho, es uno de lo más preciosos dones que a los hombres dieron los cielos; con ella no pueden igualarse los tesoros que encierra la tierra ni el mar encubre; por la libertad, así como por la honra, se puede y debe aventurar la vida, y, por el contrario, el cautiverio es el mayor mal que puede venir a los hombres (CERVANTES, 1605, p. 742). ${ }^{3}$
}

Já, nos anos 60, aspirando por mudanças políticas nos Estados Unidos da América, Bob Dylan defende a liberdade, como um referencial “de todos e para todos" na canção Blowin' in the wind (CESAR, 1990, p. 46): “Yes, ' $n$ ' how many years can some people exist: before they're allowed to be free?" (DYLAN, 1963).

Assim, como não poderia ser diferente, grande relevância também é dada pela dogmática jurídica ao tema, de modo que "ao Direito positivo interessa cuidar apenas da liberdade objetiva (liberdade de fazer, liberdade de atuar", sendo costumeiro falar em "liberdades", agrupáveis em cinco grandes grupos: liberdade da pessoa física; liberdade pensamento; liberdade de expressão coletiva; liberdade de ação profissional; liberdade de

\footnotetext{
3 Liberdade, Sancho, é um dos dons mais preciosos que os homens deram aos céus; com ela os tesouros que a terra contém não podem ser igualados nem o mar oculta; para a liberdade, assim como para a honra, a vida pode e deve ser aventada, e, ao contrário, o cativeiro é o maior mal que pode vir aos homens (tradução livre).
} 
conteúdo econômico e social (SILVA, 2013, p. 236-237, grifo do autor).

Nesse viés, A Declaração Universal dos Direitos Humanos, ao longo de sua redação, contempla a liberdade em sentido lato em seus vários matizes, como, por exemplo, nos artigos 1, 3, 4, 9, 13, 18, 19, entre outros (NAÇÕES UNIDAS, 1948).

No plano jurídico interno, a Constituição Federal privilegia a liberdade, como um direito individual fundamental, ao passo em que coloca como objetivo da República brasileira a construção de uma "sociedade livre" (BRASIL, 1988).

Como perceptível, o estado de arte conduz a um apreço interseccional da liberdade, o que geraria um certo repouso dogmático. No entanto, com estudos mais recentes, passa-se a questionar como, de fato, se dá o exercício da liberdade.

Entrementes, quanta liberdade existe na hora de escolher algo? Os recentes estudos da economia comportamental, sobretudo por Richard Thaler, ganhador do Prêmio Nobel de 2017, demonstram que "pequenas mudanças na forma como as diversas alternativas nos são apresentadas pode influenciar muito a nossa tomada de decisão" (DANA, 2017).

\section{POSITIVISMO, DIREITO COMPORTAMENTAL E NUDGING: A CIÊNCIA JURÍDICA SOB UMA NOVA PERSPECTIVA}

Dentre os teóricos do positivismo normativista, destaca-se a figura de Hans Kelsen (1881-1973), segundo o qual o direito é uma ordem (leia-se, sistema coeso de regras) da conduta humana (KELSEN, 2000, p. 5). O jurista de Viena aborda esse conceito também em "Teoria Pura do Direito":

[...] quando confrontamos uns com os outros os objetos que, em diferentes povos e em diferentes épocas, são designados como "Direito", resulta logo que todos eles se apresentam como ordens de conduta humana. Uma "ordem" e um sistema de normas cuja unidade é constituída pelo fato de todas elas terem o mesmo fundamento de validade. E o fundamento de validade de uma ordem normativa é - como veremos uma norma fundamental da qual se retira a validade de todas as normas pertencentes a essa ordem (KELSEN, 1998, p. 21)

Nesse aspecto, Nader (2013) entende que as normas jurídicas são “fórmulas de agir”, que fixam o comportamento interpessoal a fim de possibilitar a convivência social. Assim, a Constituição Federal diz que: "ninguém será obrigado a fazer ou deixar de fazer alguma coisa senão em virtude lei” (BRASIL, 1988). 
Ao longo do tempo, a visão da tradição jurídica, da qual o sistema brasileiro não destoa, é a de que os sujeitos agem, de modo racional, quando num ambiente normal (GAZZANIGA, 2008, p. 413) $)^{4}$.

Assim sendo, algumas previsões do modelo jurídico tradicional são simplesmente equivocadas, como, por exemplo, o fato de que os indivíduos podem ser mais resolutos ou prestativos do que previsto comumente, o que interessa ao Direito. Em outros casos, a economia não prevê ou prevê, incorretamente, a ausência de reações, pois parte do pressuposto de que as escolhas são invariáveis, independente de como formulado o problema. Todavia é bem estabelecido de que as pessoas reagem diferentemente a resultados em potencial, a depender de como eles são expressados (SUNSTEIN; JOLLS; THALER, 1998, p. 90-91).

Ocorre que, nos últimos anos, estudos comportamentais apontam que os seres humanos "não se comportam de maneira 'racional' na acepção tradicional do termo" (HORTA, 2017, p. $653)$.

Por isso, segundo Aguiar (2006, p. 213), a análise comportamental do Direito consiste num "método de análise e crítica científica do direito", levando-se em conta os seguintes pressupostos conceituais:

a) o direito, redefinido como tecnologia jurídica, se insere em um processo de experimentação social contínua baseado em quase-experimentos de intervenção na realidade social; b) as normas jurídicas são meios de imposição de contingências sociais normativas, destinas a modelar, manter, modificar e, eventualmente, extinguir os padrões comportamentais humanos considerados, com base em pressupostos empiricamente válidos sobre o comportamento humano, como necessários à obtenção de metas sociais politicamente definidas (AGUIAR, 2006, p. 213).

Uma abordagem comportamental do direito oferece uma série de novas propostas a fim de aprimorar o funcionamento do sistema jurídico. Como resultado disso, surgem novas questões sobre erros possíveis entre os agentes, públicos e particulares, porém cria sérias dúvidas sobre a reflexão antipaternalista de algumas análises econômicas do Direito (SUNSTEIN; JOLLS; THALER, 1998, p. 90-91).

Ademais, aparecem críticas como o risco à autonomia de vontade do particular (liberdade) em decorrência do uso indiscriminado da política behaviorista na produção de normas e ao papel do Estado em elaborar políticas que retiram do indivíduo essa liberdade de escolha, uma vez que os fins a serem alcançados são, previamente, prescritos pelo mecanismo

\footnotetext{
${ }^{4}$ Gazzaniga (2008, p. 413) diz que: "The complex set of ideas that has emerged was largely established during times when few worried about notions of determined brains or social rules. The view of humans, embodied in the law, was simples and straightforward. The human, according to this view, is a practical reasoner functioning in a normal environment".
} 
do $n u d g e^{5}$ (RIBEIRO; DOMINGUES, 2018, p. 468).

Thaler e Sunstein (2008, p. 6), de outro modo, argumentam que os nudges não retiram a liberdade de escolha da população, mas apenas trabalham as arquiteturas de escolha para que as pessoas mudem significativamente suas atitudes em prol do objetivo. Nudges não são mandados imperativos, os sujeitos tem a opção de não seguir a ideia desenvolvida a partir da economia comportamental.

Aguiar (2014, p. 264-269) então concebe a norma jurídica, não como objetos linguísticos com significados, mas como "redes de padrões comportamentais complexos", de modo que aqueles ditos objetos servem apenas para extração dos comportamentos, por meio de seus intérpretes. Além disso, entende que os enunciados normativos (contingências jurídicas, para o autor) são somente um dos elementos das normas, enquanto regras de controle de comportamento, ao lado de metas sociais e premissas comportamentais relevantes, o que permitiria: [...] jurista, em especial ao aplicador do direito, analisar os fins sociais das normas e as premissas comportamentais que governam a obtenção ou não de tais fins, mediante a imputação de sanções a determinados comportamentos humanos.

\section{A TUTELA INTERNACIONAL DOS DIREITOS HUMANOS E O NOVO PRISMA DE PROTEÇÃO A PARTIR DA ECONOMIA COMPORTAMENTAL}

A concepção contemporânea de direitos humanos atrela-se ao movimento extremamente recente de internacionalização dos direitos humanos, que surgiu como resposta histórica, a partir do Pós-Guerra, aos horríveis crimes cometidos durante o nazi-fascismo (PIOVESAN, 2017, p. 50-51).

Isso em consideração, como adverte Guerra (2012, p. 135), ao “[...] fato paradoxal de os seres humanos serem relativamente universais”, já que se verifica, com a globalização, uma constante atenuação das fronteiras do nacional e internacional (VARELLA, 2012, p. 579).

Existem várias concepções sobre a globalização, porém é lhes comum a constatação do maciço aumento da interação interestatal, desde o início dos anos noventa. Mais do que o fenômeno de interdependência entre as nações, diz-se que conduz a uma fusão parcial de países, antes separados - ainda que raramente defenda-se a tese do apagamento completo das fronteiras

\footnotetext{
${ }^{5}$ Neste trabalho, adota-se o conceito de nudges como sendo "estímulos de comportamento" (COSTA, $2017, \mathrm{P}$. 92). No mesmo sentido, eles funcionam como um guia para fazer com que as pessoas tenham suas vidas simplificadas, enfrentem menos burocracias e que ao dia-a-dia delas seja agregada maior segurança (SOUZA; RAMOS; PERDIGÃO, 2018, p. 239).
} 
(VON BOGDANDY, 2004, p. 888).

Muito embora a globalização e, ainda mais, a internacionalização dos direitos humanos sejam fenômenos recentes, Alvarado (2016, p. 25-26) observa a persistência do debate, repetido exaustivamente ao longo da história, entre as teorias dualista e monista ${ }^{6}$, sendo que estas consistem em autênticos mortos-vivos inábeis a explicar o atual estado da arte, pois o cenário mudou exponencialmente, na medida em que há um movimento de desestatização do direito internacional, devido à multiplicação de sujeitos e fontes normativas, como também mostra-se bastante difícil esta divisão hermética em dois blocos normativos puros.Devido ao presente recorte temático do presente, tal questão não será aprofundada.

Uma primeira dificuldade da tutela internacional advém da soberania, que é um princípio previsto na Carta da $\mathrm{ONU}^{7}$, mas que vivencia uma crise ${ }^{8}$, considerando, especialmente:

[...] a dificuldade de conciliar a noção de soberania do Estado com a ordem internacional, de modo que a ênfase na soberania do Estado implica sacrifício maior ou menor do ordenamento internacional e, vice-versa, a ênfase neste se faz com restrições de grau variável aos limites da soberania, há algum tempo tomada ainda em termos absolutos; [...] (BONAVIDES, p. 133).

Apenas para ilustrar a problemática, em 2017, a agência oficial de comunicação da Coreia do Norte noticiou a mensagem de que não regrediria o programa nuclear e que a decisão do Conselho de Segurança da Organização das Nações Unidas era "uma violação violenta de nossa soberania" (O GLOBO, 2017).

Visto isto, para operar o controle da efetividade de seus tratados, o Direito

\footnotetext{
${ }^{6}$ Segundo Alvarado (2016, p. 17-18), o dualismo surge na obra de Triepel no início do século XX, de modo a propor que o direito internacional e o interno carregariam caracteres peculiares que os distinguiria. Nesse passo, o objetivo do primeiro seria regulamentar as relações entre nações, sendo fundamentado pela vontade delas e dirigido tão somente a eles próprios. Diante disso, para que fosse aplicado, internamente, o direito internacional, seria necessário transformá-lo em norma jurídica doméstica. Em caso de conflito, portanto, aplicar-se-iam as regras de solução daquele ordenamento pátrio e dependeria da natureza do ato ou meio que incorporou a norma internacional. De outra banda, Kelsen, preocupado com os requisitos para a sua teoria pura do direito, pautada, especialmente, pelos signos de unidade e integração da ordem jurídica, negava a existência de dois ordenamentos distintos. Sugere assim que o direito internacional independe de um ato de incorporação para que tenha efeitos a nível interno, visto que aquele é fonte de subordinação da ordem interna - anote-se, entretanto, que há também quem defenda a prevalência do direito nacional. Finalmente, cabe registrar que há quem defenda teorias intermediárias, pelas quais haveria unidade entre os ordenamentos, mas não subordinação.

${ }^{7} \mathrm{O}$ artigo 2 dispõe que: “A Organização e seus membros, para a realização dos propósitos mencionados no artigo 1, agirão de acordo com os seguintes Princípios: 1 . A Organização é baseada no princípio da igualdade soberana de todos os seus membros" (NAÇÕES UNIDAS, 1945).

${ }^{8}$ Mazzuoli (2002, p. 175) defende, portanto, a reformulação do conceito para que se adeque à proteção dos seres humanos. Nesse viés: "[...] é que o sistema de proteção internacional dos direitos humanos das Nações Unidas, não ameaça a soberania das Nações Unidas não ameaça a soberania nacional dos Estados, uma vez que o seu caráter de proteção é complementar e subsidiário, em que se reconhece primordialmente aos Estados a incumbência pela efetiva proteção". Assim, "pode-se concluir que não há conceito mais alheio ao da proteção internacional dos direitos humanos que o conceito tradicional de soberania".
} 
Internacional conta com instrumentos, que têm se aperfeiçoado, mormente depois dos anos noventa, principalmente em três áreas: humanitário, ambiental e econômico. Consistem, com feito, em capacidades dadas pelos próprios Estados aos demais ou às Organizações Internacionais de fiscalização de suas atitudes, a exemplo da Organização Internacional do Trabalho (OIT). Com exceção do último, são típicos instrumentos de controle: "relatórios; inspeções; criação de Organizações Internacionais específicas para a vigília; estímulos positivos e negativos de certos Estados ou Organizações Internacionais" (VARELLA, 2018, p. 121).

O último item assemelha-se ao que dispõe Benevides Filho (2013, p. 369), segundo o qual a sanção consiste numa "reação ou retribuição prevista no ordenamento normativo, externando esta uma feição premial (sanção premial), quando o agente adota a conduta aprova ou esperada, ou um caráter punitivo (sanção negativa), quando o ato praticado é indesejado ou dissonante".

Sabe-se, segundo Brant e Marques (2015, p. 354), que “os Estados são, ainda nos dias de hoje, profundamente ciosos da sua qualidade de agentes soberanos, e, portanto, reticentes a qualquer legislação que pudesse agir contra eles mesmos".

Não se nega a ausência de meios coercitivos para solução dos conflitos internacionais, que não a guerra, porém, considerando a predileção institucionalizada pela resolução pacífica, como meios diplomáticos e jurídicos, tem-se nesta um meio mais equilibrado para a convivência e sobrevivência humana (CASELLA; ACCIOLY; NASCIMENTO, 2012). Até porque, por exemplo, "o sistema coercitivo das Nações Unidas, no âmbito da Corte Internacional de Justiça, parece inadaptado e ineficiente” (BRAT; MARQUES, 2015, p. 369).

De tal modo, indo para além do dogma da completude ${ }^{9}$, a discussão sobre o direito comportamental internacional (behavioral internacional law) é necessária, bem como os estudos sobre os meios de contribuição para a tutela dos direitos humanos a partir daquele ramo jurídico.

Nessas (rel)ações, os estados e outros sujeitos internacionais são racionais ao criar o direito internacional, cumprindo-o, violando-o ou impondo isso? Predominam as suposições de que agem em perfeita racionalidade tanto os estados quanto os "decision-makers" daqueles que são determinantes sobre o que relevante na conduta deles no Direito Internacional (BROUDE,

\footnotetext{
${ }^{9}$ Sobre isso, Marques (2013, p. 42) diz que: "É clássico o entendimento de que o ordenamento jurídico seria completo devido à presença de normas jurídicas aptas e suficientes para solucionar todo e qualquer caso levado ao Judiciário para resolução, ainda que para tanto, tenha de se valer de instrumentos de integração do Direito. O Direito não possuiria lacunas"
} 
2013, p. 7-8).

O ponto fulcral subjacente ao estudo da teoria comportamental é a ideia do "bounded rationality", que reconhece que as capacidades cognitivas do ser humana não são perfeitas ou infinitas. Assim sendo, a pretensão da agenda comportamental é explorar as características do real processo de realizar escolhas dos diferentes tipos de atores em diversas circunstâncias (BROUDE, 2013, p. 22-23).

Nesse contexto, a ferramenta do direito comportamental e do nudging pode ser utilizada em favor do ser humano no cenário internacional. Nesse viés, segundo Teichman e Zamir (2018), mostra-se mais favorável o uso do nudging do que no direito interno por pelo menos duas razões: a) dados os grandes desafios enfrentados pelo Direito Internacional, as propostas de incentivar a comunidade internacional utilizar medidas mais invasivas são menores do que no âmbito doméstico; b) o receito quanto ao abalo à autonomia individual é muito menor quando do uso de nudges para influenciar estados ou outras organizações do que pessoas.

Afinal, como os outros ramos jurídicos, o direito internacional foi criado pelo povo, aplicado por ele e refere-se às condutas humanas. Como tal, pode-se beneficiar dos estudos psicológicos sobre as percepções, julgamentos e escolhas dos seres humanos (TEICHMAN; ZAMIR, 2018).

Para demonstrar a viabilidade do proposto, Teichman e Zamir (2018) citam, como exemplo, a questão dos refugiados, que é um problema humanitário bastante atual. Nos últimos anos, o entendimento dos oficiais e acadêmicos da ONU é o de que a proibição de banir ou expulsar os refugiados ou solicitantes de asilo quando em perigo de vida ou liberdade, prescrita na Convenção de Refugiados de 1951, estende-se ao asilo daqueles que buscam entrar em outro país. Todavia a prática dos Estados ou de seus tribunais locais destoa dessa visão, na medida em que se distingue aqueles que já estão no país e os que querem nele ingressar. Uma explicação poderia ser a aversão à perda, uma vez que os requerentes de asilo já estão no território e não tentando entrar. Assim, ao elaborar as políticas públicas, os políticos podem se mostrar mais relutante em permitir a entrada do que expulsar um requerente de asilo. Outra explicação seria o "identifiability effect", isto é, segundo estudos psicológicos, seria a diferença de reação entre os indivíduos identificados e os não identificados, para os primeiros as emoções, como compaixão e aflição, eram mais fortes.

Outra possível aplicação teórica dos pressupostos comportamentais, seria o viés do status quo, segundo o qual as pessoas tendem a preferir um estado de coisas atual do que outras alternativas que poderiam deixa-las melhor, em vista ao receio dos riscos e da incerteza, pode 
ajudar a entender melhor as nuances acerca da celebração de tratado. Ademais, o relativo aumento da judicialização no direito internacional proporciona também um terreno fértil para estudos internacionais como tomadores de decisões. Por exemplo, mesmo quando são permitidos votos de divergências, há um certo mal-estar nisso, pois encoraja um "adversarial collaboration" no juízo, levando a um alto número de julgados unânimes nos tribunais domésticos ${ }^{10}$ (BROUDE, 2013, p. 58 e 66).

Observada a viabilidade disso, Van Aaken (2014, p. 480) defende que as escolas das Relações Internacionais e do Direito Internacional podem usar os argumentos sistêmicos feitos pelos economistas comportamentais e psicológicos para compreender a "choice architecture" no direito internacional como também nas normas e suas repercussões nas relações internacionais.

No que diz respeito, à efetividade das decisões das Cortes Internacionais, é possível, aparentemente, dada a incipiência do estudo, sugerir e reconhecer alguns pontos para aprimorála. Inicialmente, importante registrar dois dos dez nudges importantes, segundo Sustein (2015, p. 113-114), a saber: divulgação (disclosure) e informar as pessoas sobre a natureza e consequências de suas escolhas passadas. O motivo da escolha é que eles podem ser usados na proteção internacional aos direitos humanos, como mecanismos de efetivação pelos estados das normas internacionais e das decisões dos tribunais internacionais, de modo voluntário.

Por exemplo, a Corte Interamericana de Direitos Humanos costuma (por exemplo, nos casos Gomes Lund e outros versus Brasil e Herzog versus Brasil), quando da prolação de sentença condenatória, a publicação do resumo da sentença em jornais escritos, além de elaborar um sítio eletrônico contendo-a na íntegra, o que é louvável, visto que afeito ao nudge da divulgação.

Entretanto, a fim de melhor cumprir o fim proposto, poder-se-ia determinar a divulgação do resumo da sentença na televisão aberta. Afinal, segundo a Pesquisa Brasileira de Mídia 2016 - Hábitos de Consumo de Mídia pela População Brasileira, "quase 90\% dos brasileiros se informam pela televisão sobre o que acontece no país, sendo que $63 \%$ têm na TV o principal meio de informação" (GLOBO, 2017).

Assim, mesmo considerando a incipiência do direito internacional comportamental, percebe-se que é de grande valia para a efetivação das normas e das decisões internacionais o uso de nudges.

\footnotetext{
${ }^{10}$ Por exemplo, a CADH (1969) prevê, em seu artigo 66, item 2, que: "se a sentença não expressar no todo ou em parte a opinião unânime dos juízes qualquer deles terá direito a que se agregue à sentença o seu voto dissidente ou individual".
} 


\section{CONSIDERAÇÕES FINAIS}

Com base no exposto, verifica-se o grande apreço, em especial, na cultura ocidente, à noção de liberdade, do qual o Direito não destoa, ao passo em que tutela esse bem como direito fundamental do Brasil e, na ordem internacional, como direito humano. Todavia, com os recentes estudos, questiona-se o quanto de liberdade existe nas escolhas.

Ainda assim, o estado de coisas do Direito permanece com a premissa de que o sujeito, ao agir em (des)conformidade com os enunciados normativos, o faz de forma racional e normal, o que é criticado pela perspectiva comportamental do Direito, o que, por consequência, ocasiona reflexões, desafios e peculiaridades novos.

Ao estudar, especificamente, o Direito Internacional e a sua proteção dos Direitos Humanos, nota-se algumas dificuldades para sua operabilidade, como é o caso, por exemplo, do conceito tradicional de soberania.

Como há uma preferência do direito internacional pela resolução pacífica dos conflitos, nota-se a necessidade de superar o dogma da completude, para valer-se das noções do direito internacional comportamental.

Isso porque, assim como no âmbito doméstico, seja com pessoas seja com empresas, os atores do Direito Internacional também não agem em perfeita racionalidade. Na verdade, a aplicação do direito comportamental no cenário internacional, mostra-se mais favorável porque lá é mais incentivado o uso de meios menos invasivos e porque o medo da mitigação da autonomia da vontade é bem menor.

Desse modo, verificam-se algumas medidas que (também) serviriam no campo internacional, como por exemplo, os pressupostos do status quo, do indefiability effect, da aversão à perda, etc.

No pertinente à efetividade do direito e das decisões internacionais, dois nudges são de grande valia, quais sejam, o da divulgação e o da informação às pessoas sobre a natureza e consequência das escolhas passadas.

Para ilustrar, sugere-se, como exemplo, a divulgação do resumo das sentenças condenatórias da Corte Interamericana de Direitos Humanos não só em meios físicos, como já é feito, mas também na televisão aberta, visto que, segundo recente estatística, quase $90 \%$ dos brasileiros se informa por tal meio de comunicação. 
Finalmente, o objeto do presente artigo é bastante novo, de modo que, mais do que conclusões e descrições estáticas, verifica-se a necessidade de uma (re)identificação do Direito Internacional, onde os nudges despontam como ferramentas úteis para a consecução dos fins do direito das gentes.

\section{REFERÊNCIAS}

AGUIAR, J. C. Análise Comportamental do Direito: fundamentos para uma abordagem do Direito como ciência comportamental aplicada. 2006. Tese (Doutorado em Direito). Pósgraduação em Direito, Universidade Federal de Santa Carina. Disponível em: <http://dominiopublico.mec.gov.br/download/teste/arqs/cp021156.pdf>. Acesso em: 03 dez. 2018.

Análise Comportamental do direito: uma abordagem do direito como ciência do comportamento humano aplicada. Revista do Programa de Pós-Graduação em Direito da UFC. $\quad$ v. $34, \quad$ jul./dez. $2014 . \quad$ Disponível em: $<$ https://aprender.ead.unb.br/pluginfile.php/278147/mod_resource/content/1/Ana\%CC\%81lise \%20Comportamental\%20do\%20Direito.pdf>. Acesso em: 08 dez. 2018.

ALVARADO, Paulo Andrea Acosta. Zombis vs. Frankenstein: sobre las relaciones entre el derecho internacional y el derecho interno. Estudios Constitucionales. 14. n. 1. 2016. pp. 1560 .

BENEVIDES FILHO, Maurício. O que é Sanção?. Revista da Faculdade de Direito, Fortaleza, v. $34, \quad$ n. 1 , p. 355-373, jan./jun. 2013. Disponível em: <http://www.repositorio.ufc.br/handle/riufc/11850>. Acesso em: 08 dez. 2018.

BONAVIDES, Paulo. Ciência política. 25 ed. - São Paulo: Malheiros, 2018.

BRANT, L. N. C.; MARQUES, L. C. A. A sanção coercitividade como instrumento de eficácia da norma do Direito Internacional. Revista da Faculdade de Direito da UFMG, Belo Horizonte, n. 67, pp. 341-372, jul./dez. 2015. Disponível em: $<$ https://www.direito.ufmg.br/revista/index.php/revista/article/viewFile/1740/1653>. Acesso em: 09 dez. 2018.

BRASIL. Constituição da República Federativa do Brasil. Diário Oficial da República Federativa do Brasil. Brasília, DF, 1988. Disponível em: <http://www.planalto.gov.br/ccivil_03/constituicao/constituicao24.htm>. Acesso em: 25 nov. 2018.

BROUDE, Tomer. Behavioral International Law. 163 University of Pennsylvania Law Review. N. 12-13. 2013.2 Jerusalem. Disponível em: <https://papers.ssrn.com/sol3/papers.cfm?abstract_id=2320375>. Acesso em: 15 dez. 2018.

CASELlA, P. B.; ACCIOLY, H.; NASCIMENTO, G. E. Manual de direito internacional público. 20 ed. - São Paulo: Saraiva, 2012. 
CERVANTES, Miguel de. El ingenioso Hidalgo Don Quijote de la Mancha (1605). Vol. II. Disponível em: < http://www.ebooksbrasil.org/adobeebook/quijote2.pdf>. Acesso em: $01 \mathrm{dez}$. 2018.

CESAR, L. V. Poesia e Política nas Canções de Bob Dylan e Chico Buarque. 1990. Dissertação (Mestrado em Letras). Setor de Ciências Humanas, Letras e Artes, Universidade Federal do Paraná. Disponível em: https://www.acervodigital.ufpr.br/bitstream/handle/1884/24378/?sequence=1>. Acesso em: 01 dez. 2018.

CORTE INTERAMERICANA DE DIREITOS HUMANOS (CIDH). Caso Herzog e outros vs. Brasil. 15 mar. 2018. Disponível em: $\langle$ http://www.corteidh.or.cr/docs/casos/articulos/seriec_353_por.pdf $>$. Acesso em: 16 dez. 2018.

Caso Gomes Lund E Outros ("Guerrilha Do Araguaia") Vs. Brasil. 24 nov. 2010. Disponível em: <http://www.corteidh.or.cr/docs/casos/articulos/seriec_219_por.pdf>. Acesso em: 16 dez. 2018.

COSTA, N. L. M. "Nudge" como abordagem regulatória de prevenção à corrupção pública no Brasil. Revista de informação legislativa, v. 54, n. 214, p. 91-111, abr./jun. 2017. Disponível em: <https://www12.senado.leg.br/ril/edicoes/54/214/ril_v54_n214_p91.pdf>. Acesso em: 08 dez. 2018.

DANA, Samy. Nobel de Economia defende "empurrãozinho" na direção certa, 2017. Disponível em: <http://g1.globo.com/economia/blog/samy-dana/post/nobel-de-economiadefende-empurraozinho-na-direcao-certa.html>. Acesso em: 25 nov. 2018.

DEL'OLMO, Florisbal de Souza; GIMENEZ, Charles Paula Colet. International Conflicts and Peace Agreements: The Case of the Revolutionary Armed Forces and the Colombian State. Revista Juridica, [S.1.], v. 4, n. 53, p. 85 - 107, dez. 2018. ISSN 2316-753X. Disponível em: <http://revista.unicuritiba.edu.br/index.php/RevJur/article/view/3211/371371728>. Acesso em: 23 abr. 2020. doi:http://dx.doi.org/10.21902/revistajur.2316-753X.v53i4.3211.

DYLAN, Bob. Blowin' in the wind. 1963. Disponível em: <https://www.letras.mus.br/bobdylan/11904/traducao.html>. Acesso em: $01 \mathrm{dez} .2018$.

GAZZANIGA, Michael S. The Law and Neuroscience. Neuron. 2008. Disponível em: <https://www.cell.com/action/showPdf?pii=S0896-6273\%2808\%2900895-7>. Acesso em: 02 dez. 2018.

TV é o meio preferido de $63 \%$ dos brasileiros para se informar, e internet de $26 \%$, diz pesquisa. Globo. Economia. 2017. Disponível em: < https://g1.globo.com/economia/midia-emarketing/noticia/tv-e-o-meio-preferido-por-63-dos-brasileiros-para-se-informar-e-internetpor-26-diz-pesquisa.ghtml>. Acesso em 16 dez. 2018.

GUERRA, Sidney. Direitos Humanos \& cidadania. - São Paulo: Atlas, 2012.

HOBSBWAN, Eric. A Era das Revoluções. - São Paulo: Paz e Terra, 2012. 
KELSEN, Hans. Teoria Geral do Direito e do Estado. Trad. Luiz Carlos Borges. 3 ed. - São Paulo: Martins Fontes, 2000.

. Teoria Pura do Direito. 6 ed. - São Paulo: Martins Fontes, 1998.

MAZZUOLI, Valerio de Oliveira. Soberania e a proteção internacional dos direitos humanos: dois fundamentos irreconciliáveis. Revista de Informação Legislativa. Brasília, a. 39, n. 156, out./dez. 2002. Disponível em: $<$ http://www2.senado.leg.br/bdsf/bitstream/handle/id/496888/RIL156.pdf?sequence=1\#page= 160>. Acesso em: 15 dez. 2018.

MARQUES, Elmer da Silva. Releitura do dogma da completude sob a ótica da textura aberta do Direito em H. L. A. Hart. Revista Direito e Práxis. Vol. 4, n. 7, 2013, pp. 25-47. Disponível em: <https://www.e-publicacoes.uerj.br/index.php/revistaceaju/article/view/6784>. Acesso em: 15 dez. 2018.

NAÇÕES UNIDAS. Declaração Universal dos Direitos Humanos. 1948. Disponível em: <http://unesdoc.unesco.org/images/0013/001394/139423por.pdf>. Acesso em 25 nov. 2018.

Carta das Nações Unidas. 1945. Disponível em: <https://nacoesunidas.org/wp-content/uploads/2017/11/A-Carta-dasNa\%C3\%A7\%C3\%B5esUnidas.pdf >. Acesso em: 09 dez. 2018.

NADER, Paulo. Introdução ao estudo do Direito. 35 ed. - Rio de Janeiro: Forense, 2013.

Coreia do Norte promete retaliar em resposta a sanções da ONU. O Globo. 07 ago. 2017. Mundo. Disponível em: <https://oglobo.globo.com/mundo/coreia-do-norte-promete-retaliarem-resposta-sancoes-da-onu-21676538>. Acesso em: 15 dez. 2018.

PIOVESAN, Flávia. Direitos Humanos e Justiça Internacional: um estudo comparativo dos sistemas regionais europeu, interamericano e africano. 7 ed. rev. ampl. e atual. - São Paulo: Saraiva, 2017.

RIBEIRO, M. C. P.; DOMINGUES, V. H. Economia comportamental e direito: a racionalidade tem mudança. Revista Brasileira de Políticas Públicas. vol. 8. N. 2. Ago. 2018. Disponível em: $<$ https://www.publicacoesacademicas.uniceub.br/RBPP/article/viewFile/5218/3760>. Acesso em: 08 dez. 2018.

SILVA, José Afonso da. Curso de Direito Constitucional Positivo. 36 ed. - São Paulo: Malheiros, 2013.

SOUZA, Luciana Cristina; RAMOS, Karen Tobias França; PERDIGÃO, Sônia Carolina Romão Viana. Análise crítica da orientação de cidadãos como método para otimizar decisões públicas por meio da técnica nudge. Revista Brasileira de Políticas Públicas, Brasília, v. 8, nº 2, 2018 p.234-250. Disponível em: https://www.publicacoesacademicas.uniceub.br/RBPP/article/view/5314/3993>. Acesso em: 23. dez. 2018.

SUNSTEIN, C. R.; JOLLS, C.; THALER, R. T. A behavioral approach to Law and Economics. Coease-Sander Institute for Law \& Economics Working Paper. n. 55. 1998. Disponível em: 
<https://chicagounbound.uchicago.edu/cgi/viewcontent.cgi?article=1003\&context=law_and_e conomics>. Acesso em: 08 de dez. 2018.

SUNSTEIN, Cass. Nudging: um guia muito breve. In: ÁVILA, F; BIANCHI, A. M. Guia de Economia Comportamental e experimental. 1 ed., rev., e atual. Trad. Laura Teixeira Motta e Paulo Futagawa. - São Paulo: EconomiaCompartamental.org, 2015.p. 109-114.

TEICHMAN, Doron; ZAMIR, Eyal. Behavioral Analysis of International Law: On Lawmaking and Nudigng. Hebrew University of Jerusalem Legal Studies Reseach Paper Series. Jerusalem, n. 18. 2018. Disponível em: <https://papers.ssrn.com/sol3/papers.cfm?abstract_id=3110367>. Acesso em: 09 dez. 2018.

THALER, Richard H.; SUNSTEIN, Cass R. Nudge : improving decisions about health, wealth, and happiness. New Haven \& London: Yale University Press. 2008

VAN AAKEN, Anne. Behavioral International Law and Economics. Harvard International Law Journal, vol. 55, n. 2., 2014. Disponível em: < http://www.harvardilj.org/wpcontent/uploads/552vanAaken.pdf>. Acesso em: 09 dez. 2018.

VON BOGDANDY, Armin. Globalization and Europe: How to square democracy, globalization and Internacional Law. The European Journal of Internacional Law. Vol. 15. N. 5. 2004. Disponível em: <https://academic.oup.com/ejil/article/15/5/885/533488>. Acesso em: 15 dez. 2018.

VARELLA, M. D. Internacionalização do direito: Direito internacional, globalização e complexidade. 2012. 606 f. Tese (Livre-Docência em Direito Internacional), Universidade de São Paulo, São Paulo. 2012.

Direito Internacional Público. 7 ed. - São Paulo: Saraiva Educação, 2018. 